\title{
ALKALI PRETREATED OF WHEAT STRAW AND ITS ENZYMATIC HYDROLYSIS
}

\author{
Lirong Han\#, Juntao Feng", Shuangxi Zhang, Zhiqing Ma, Yonghong Wang, Xing Zhang*
}

R\&D Center of Biorational Pesticides, Northwest A \& F University, 22 Xinong Road, Yangling, Shaanxi 712100, China.

Submitted: December 08, 2009; Returned to authors for corrections: June 29, 2011; Approved: January 16, 2012.

\begin{abstract}
The efficiency of enzymatic hydrolysis of cellulose can be improved by various pretreatments of the substrate. In order to increase the efficiency of enzymatic saccharification of the wheat straw, we determined the effect of different pretreatments on the physical structure, chemical components and enzymatic saccharification of wheat straw. Our results showed that combination of grinding and sodium hydroxide $(\mathrm{NaOH})$ treatment had high effect on the enzymatic hydrolysis of wheat straws. The optimal pretreatment condition was to grind the wheat straws into the sizes of 120 meshes followed by treatment with $1.0 \%$ $\mathrm{NaOH}$ for $1.5 \mathrm{~h}\left(121^{\circ} \mathrm{C} / 15 \mathrm{psi}\right)$. Under this condition, the cellulose content of wheat straw was increased by $44.52 \%$, while the content of hemicellulose and lignin was decreased by $44.15 \%$ and $42.52 \%$, respectively. Scanning Electronic Microscopy and infrared spectrum analyses showed that significant changes occurred in the structure of wheat straws after pretreatment, which is favorable for the hydrolysis and saccharification. Cellulase produced by Penicillium waksmanii F10-2 was used to hydrolyze the pretreated wheat straw and the optimal condition was determined to be $30 \mathrm{~h}$ of enzymatic reaction under the temperature of $55^{\circ} \mathrm{C}, \mathrm{pH}$ 5.5 and substrate concentration of $3 \%$.
\end{abstract}

Key words: Cellulase; Cellulose; Fermentation; Hydrolysis; Lignocellulosic; Pretreatment

\section{INTRODUCTION}

Production of biofuel from lignocellulosic feedstock has attracted significant interests worldwide. Lignocellulosic biomass including various agricultural residues is an abundant and renewable resource on earth $(1,2)$. Cellulose is the predominant polymer in lignocellulosic biomass, with a small amount of hemicellulose and lignin (3). Enzymatic hydrolysis of cellulose is a promising method for the conversion of waste cellulose to glucose. Many factors, such as the content of lignin, crystallinity of cellulose, degree of polymerization (DP), moisture content and particle size, affect the hydrolytic efficiency of the cellulose present in the lignocellulosic biomass (4-7). Lignin is one of the most abundant polymers in nature. The complex three-dimensional (3D) polyaromatic matrix of lignin prevents enzymes from accessing some regions of the cellulose polymers (8). In addition, the amorphous heteropolymer is also water-insoluble and optically inactive, which make it very difficult to be degraded.

Pretreatment of wheat straws and enzymatic hydrolysis of

*Corresponding Author. Mailing address: R\&D Center of Biorational Pesticides, Northwest A \& F University, 22 Xinong Road, Yangling, Shaanxi 712100, China.; Tel.: 86-029-87093344 Fax: 86-029-87093344.; E-mail: zhxing1952@126.com

\#: These authors contributed equally to this work. 
cellulose have been identified as the primary cost barriers in the processing of lignocellulosic materials to fermentable sugars $(9,10)$. Several different pretreatment methods have been used to facilitate the subsequent enzymatic hydrolysis of lignocellulosic materials $(11,12)$. One of the most thoroughly investigated methods is alkali pretreatment in which the alkaline solution is used to remove lignin and various uronic acid substitutions on hemicelluloses, leading to the increased accessibility of enzymes to the hemicellulose and cellulose (4). Generally, alkaline pretreatment is more effective for the subsequent hydrolysis of agricultural residues and herbaceous crops than that for the wood materials (13).

Wheat straw is a byproduct of wheat cultivation produced throughout the world. Only a small amount of wheat straw was used as livestock feeds, farmyard manure and fuel, while a large part of the wheat straw was discarded on the field or burned directly, which results in the waste of fuel resources as well as environmental contamination. Extensive studies have been carried out to extend the uses of wheat straws and increase its additional value. For example, wheat straws can be hydrolyzed into reducing sugar, which can subsequently be fermented to target products, e.g., ethanol or other chemical products by suitable microorganisms (14). The main purpose of this study was to remove lignin and hemicellulose, reduce cellulose crystallinity, and identify optimal conditions for pretreatment of wheat straws and hydrolysis of cellulose. In this paper, we report on the changes in chemical characteristics, physical properties and cellulose microstructure for pretreated wheat straw.

\section{MATERIALS AND METHODS}

\section{Wheat straw materials}

Wheat straw was purchased from a local harvest store and was smashed to the sizes of 80 meshes. After thorough washing with tap water till the washing-off water was clean and colorless, the particles of wheat straws (80 meshes) were dried in $50{ }^{\circ} \mathrm{C}$. The percentage of cellulose, hemicellulose and lignin in the dried wheat straw was $39.67 \%, 25.66 \%$ and $20.33 \%$, respectively.

\section{Microorganism}

The strain of Penicillium waksmanii F10-2, obtained from Biorational Pesticides Research and Service Center (Yangling, China), was used in this study. The $P$. waksmanii culture was maintained on agar slants $(10.0 \%$ wheat bran extract, $1.5 \%$ agar, pH 5.5) at $28^{\circ} \mathrm{C}$ and subcultured monthly.

\section{Production of cellulase}

The cellulase was produced by $P$. waksmanii F10-2 under submerged batch conditions. Fermentation mix was prepared by incorporating $2 \%$ of wheat straw of the 80 mesh as the sole carbon source into a basal medium. The basal media contains $1.1 \%$ peptone, $0.27 \% \quad \mathrm{KH}_{2} \mathrm{PO}_{4}, \quad 0.3 \% \quad\left(\mathrm{NH}_{4}\right)_{2} \mathrm{SO}_{4}$ and $0.02 \% \mathrm{MgSO}_{4} .7 \mathrm{H}_{2} \mathrm{O}$. The $\mathrm{pH}$ of each mixture was adjusted to 5.5 .

P. waksmanii inoculum was prepared by washing slant cultures with $3 \mathrm{ml}$ of sterilized water. The spore concentration was determined by hemocytometer. Two $\mathrm{ml}$ spore suspension $\left(10^{6}-10^{7}\right.$ spores $\left./ \mathrm{ml}\right)$ was inoculated into $250 \mathrm{ml}$ flask containing $100 \mathrm{ml}$ freshly prepared fermentation mixture. After 5 days of shaking $(136 \mathrm{rpm})$ at $27^{\circ} \mathrm{C}$, broth culture was filtered. The culture filtrate had an activity of $4.32 \mathrm{FPU} / \mathrm{ml}$ as measured by the methods developed previously (15). Subsequently, the broth culture were concentrated by polyethersulfone ultrafiltration membrane and the activity of condensed enzyme liquid was $46 \mathrm{FPU} / \mathrm{ml}$, which was used for further enzymatic hydrolysis experiment. One unit of enzyme was defined as the amount of enzyme capable of producing $1 \mu \mathrm{mol}$ of reducing sugars in $1 \mathrm{~min}$.

\section{Analytical methods}

Cellulose, hemicellulose and lignin contents were determined by the method developed previously (16). The content of reducing sugars was determined by the DNS method 
(17). Infrared spectra were measured by a NICOLET 330FT-

2R FT-IR spectrometry. Scanning Electron Microscopy (SEM) was performed by using a HITACHIS-570 SEM instrument and the images were taken accordingly.

\section{Pretreatment of wheat straws}

Ground wheat straw in different sizes was pretreated by sodium hydroxide $(\mathrm{NaOH})$ before enzymatic hydrolysis. Briefly, mixture of the wheat straw and $\mathrm{NaOH}(0.25-1.5 \%$ w/v) was treated with $121{ }^{\circ} \mathrm{C} / 15 \mathrm{psi}$ for 0.5 to $2.5 \mathrm{~h}$ at a solid loading condition of $10 \%(\mathrm{w} / \mathrm{v})$. The pretreated solids were washed with $800 \mathrm{~mL}$ of hot deionized water and used for determination of total solids. The solids were dried at $55^{\circ} \mathrm{C}$ and weighed.

\section{Enzymatic saccharification}

The $\mathrm{NaOH}$-pretreated straws were hydrolyzed using condensed enzyme liquid. The hydrolysis reaction was performed in $0.1 \mathrm{M}$ citrate buffer $(\mathrm{pH} 5.0)$ at $50{ }^{\circ} \mathrm{C}$ for $36 \mathrm{~h}$ with shaking $(150 \mathrm{rpm})$. The effects of different factors e.g., pretreatment, reaction time $(6-48 \mathrm{~h})$, substrate concentration $(1-11 \% \mathrm{w} / \mathrm{v})$, temperature $\left(40-60{ }^{\circ} \mathrm{C}\right)$ and $\mathrm{pH}(4-6)$ on the enzymatic hydrolysis was determined by maintaining the enzyme/substrate ratio at $25 \mathrm{FPU} / \mathrm{g}$. The percentage of hydrolysis of straws was calculated according to the following formula (18).

$$
\text { Hydrolysis rate }(\%)=\frac{\text { Reducing sugar } \times 0.9}{\text { Cellulose }+ \text { hemicellulose(in substrate })} \times 100 \%
$$

\section{RESULTS AND DISCUSSION}

\section{Pretreatment of wheat by physical and chemical methody}

The effect of wheat straw sizes on the enzymatic hydrolysis: Milling reduces the size of the materials and degree of crystallinity of lignocelluloses, which improves the susceptibility of these materials to enzymatic hydrolysis and enhances the efficiency of degradation. (19, 20). The hydrolysis efficiency was determined for the milled wheat straws with the sizes from 20 to 240 meshes. The results showed that as the size of wheat straw was reduced (especially from 40 to 120 meshes), the rate of enzymatic saccharification was increased significantly (Fig. 1). The rate of enzymatic saccharification for the 120 meshes of wheat straw was $21.50 \%$, which was 4.7 times of the untreated wheat straw. Studies have shown that without any pretreatment, corn stover with sizes of 53-75 $\mu \mathrm{m}$ was 1.5 times more productive than larger corn stover particles of 425-710 $\mu \mathrm{m}$ (20). We showed here that the enzymatic hydrolysis efficiency was not increased significantly once the size of the wheat straws was reduced to less than 160 meshes (Fig. 1). Therefore, we select 120 meshes as the optimal size for hydrolysis of wheat straws.

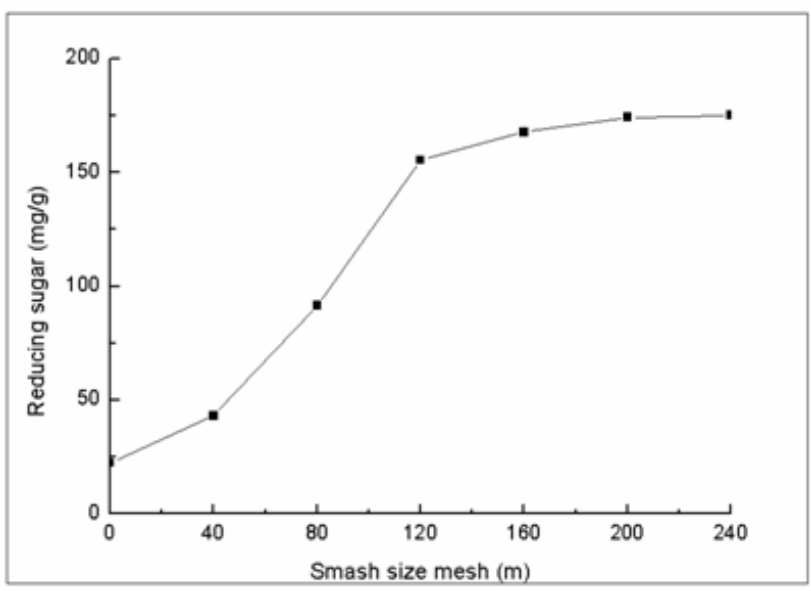

Figure 1. The effect of different particle size of wheat straw on its enzymatic hydrolysis.

Enzyme loading $25 \mathrm{FPU} / \mathrm{g}$, substrate concentration 1\%(w/v), $\mathrm{pH} 5.0$, temperature $50^{\circ} \mathrm{C}$.

The effect of $\mathrm{NaOH}$ concentration on the enzymatic hydrolysis: The mechanism of alkaline hydrolysis is believed to be saponification of intermolecular ester bonds, which crosslinks xylan hemicelluloses and other components, for example, lignin and other hemicellulose (11). The 120 meshes wheat straws were pretreated with $0.2,0.5,0.75,1.0,1.25$ 
and $1.5 \%$ of $\mathrm{NaOH}$ before enzymatic hydrolysis. The results showed that as the concentration of $\mathrm{NaOH}$ was increased, the enzymatic hydrolysis efficiency was also increased (Fig. 2). The maximal concentration of reducing sugar $(343.95 \mathrm{mg} / \mathrm{g}$ substrate) was obtained when the $\mathrm{NaOH}$ concentration reached $1.0 \%$.

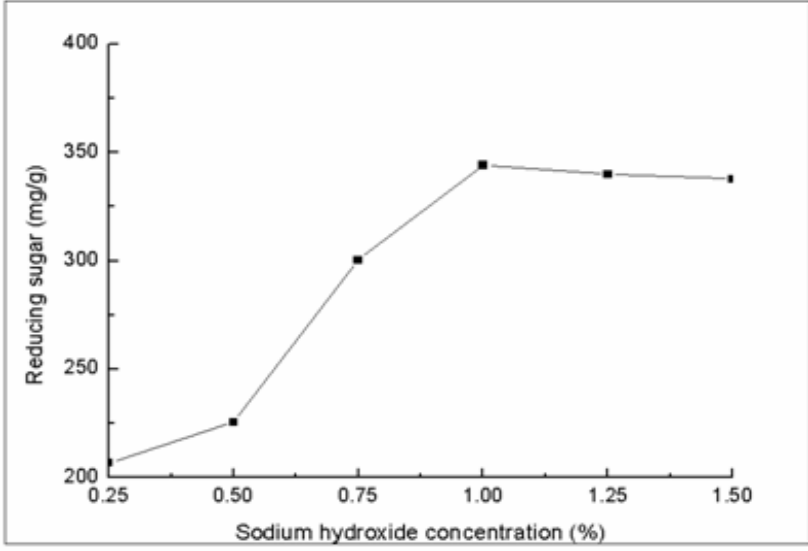

Figure 2. The effect of sodium hydroxide concentration on the enzymatic hydrolysis of wheat straw.

Enzyme loading $25 \mathrm{FPU} / \mathrm{g}$, substrate concentration 1\% (w/v), $\mathrm{pH} 5.0$, temperature $50^{\circ} \mathrm{C}$, pretreated time $2.0 \mathrm{~h}$ at $121^{\circ} \mathrm{C}$ /15psi.

The pretreatment time of $\mathrm{NaOH}$ on the hydrolysis efficiency by cellulase: The enzymatic hydrolysis efficiency was measured for the 120 meshes wheat straw pretreated with $1.0 \% \mathrm{NaOH}$ for different times. The results showed that as the $\mathrm{NaOH}$ pretreatment time was increased, the enzymatic hydrolysis efficiency was enhanced significantly (Fig. 3). However, when the pretreatment time was over $1.5 \mathrm{~h}$, the enzymatic hydrolysis efficiency was gradually decreased. This might be due to the fact that long time pretreatment with $\mathrm{NaOH}$ partially destroyed cellulose and hemicellulose, leading to the reduced concentration of reducing sugars in the enzymatic reactions. These results suggested that combinational pretreatment with milling and $\mathrm{NaOH}$ can enhance the efficiency for hydrolysis of cellulose and production of reducing sugars.

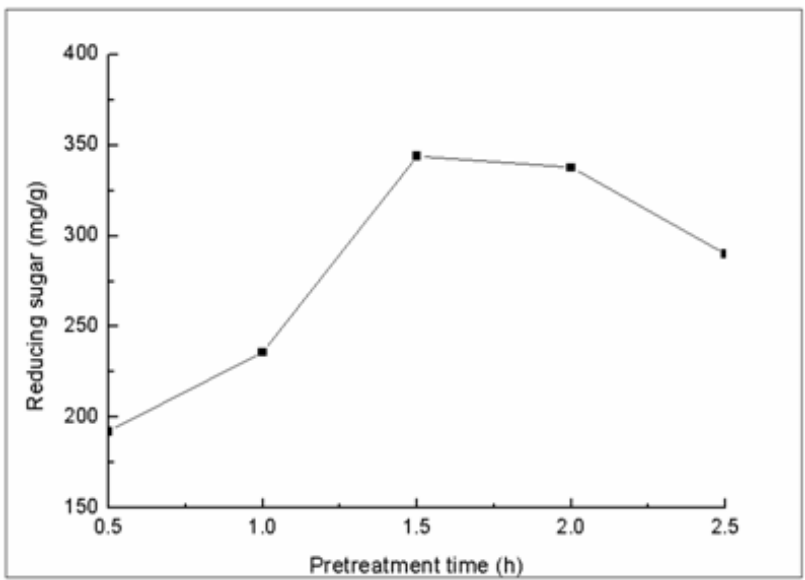

Figure 3. The effect of sodium hydroxide pretreatment time on the enzymatic hydrolysis of wheat straw.

Enzyme loading $25 \mathrm{FPU} / \mathrm{g}$, substrate concentration 1\% (w/v), $\mathrm{pH} 5.0$, temperature $50^{\circ} \mathrm{C}$, sodium hydroxide concentration $1.0 \%$.

\section{The effect of pretreatment on the components of wheat} straws

After pretreatment of the 120 meshes wheat straws with $1.0 \% \mathrm{NaOH}\left(121^{\circ} \mathrm{C} / 15 \mathrm{psi}\right)$ for $1.5 \mathrm{~h}$, the percentage of cellulose, hemicellulose and lignin was $57.33 \%, 14.33 \%$ and $11.7 \%$, respectively. Compared to the wheat straws that were not pretreated, the content of cellulose was increased by $44.52 \%$, while the content of hemicellulose and lignin was decreased by $44.15 \%$ and $42.45 \%$, respectively. The purpose of $\mathrm{NaOH}$ pretreatment was to partially remove lignin and increase the cellulose content and sample porosity, which was instrumental for the hydrolysis of wheat straw samples. Our results showed that pretreatment with $\mathrm{NaOH}$ removed lignin and at the same time partially degraded the hemicellulose.

The effect of pretreatment on the chemical structure of wheat straws

Infrared spectrum analysis for the wheat straws with or 
without $\mathrm{NaOH}$ pretreatment was shown in Fig.4. The characteristic absorption peak of the infrared spectrum in the lignin of wheat straw has a certain relationship with its category ascription. The main bond of hemicellulose and lignin was C-O-C with its characteristic absorption peak at 1462, 1425 and $1320 \mathrm{~cm}^{-1}$. Due to the presence of aromatic ring, the characteristic absorption peak was located at $1612 \mathrm{~cm}^{-1}$. The absorption peak of lignin and similar lignin group has the characteristic peak at 1510 and $1595 \mathrm{~cm}^{-1}(8,21-23)$. The characteristic absorption peak of lignin and hemicellulose in the wheat straw pretreated with $\mathrm{NaOH}$ was significantly weakened compared to that in the wheat straw without pretreatment (Fig. 4), suggesting that lignin and hemicellulose were partially degraded during the process of pretreatment.

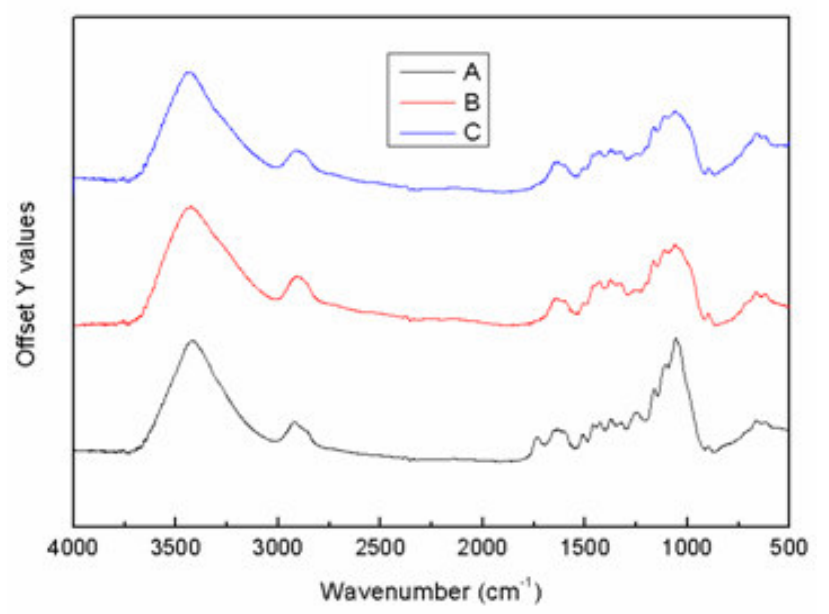

Figure 4. The FTIR spectra of (A) untreated wheat straw, (B) $\mathrm{NaOH}$-treated wheat straw at $1.0 \mathrm{~h},(\mathrm{C}) \mathrm{NaOH}$-treated wheat straw at $1.5 \mathrm{~h}$.

\section{The effect of pretreatment on the surface structure of wheat straw}

The surface structure of the wheat straws without pretreatment was tight, orderly and the texture was relatively hard (Fig. 5A). In comparison to the sample that was not subjected to enzymatic hydrolysis, there was only a slight crimp on the surface of wheat straw after enzymatic hydrolysis for $30 \mathrm{~h}$, and there was no significant change in the original structure of lignocellulose upon enzymatic hydrolysis (Fig. 5B).

In contrast, due to the partial removal of hemicelluloses and lignin, the surface of the wheat straws with $\mathrm{NaOH}$ pretreatment became soft, loosened, and contained some micro-pores on the surface of the wheat straw. (Fig. 5C). In addition, the accessible surface area was increased after pretreatment, which is favorable for action of cellulase. In comparison to the sample that was $121{ }^{\circ} \mathrm{C} / 15$ spi pretreated ,there was more severe degradation could be seen on the surface of pretreated wheat straw followed by enzymatic hydrolysis, which the lignin frame was further reduce and more holes and cracks were seen on the sample surface (Fig. 5D).
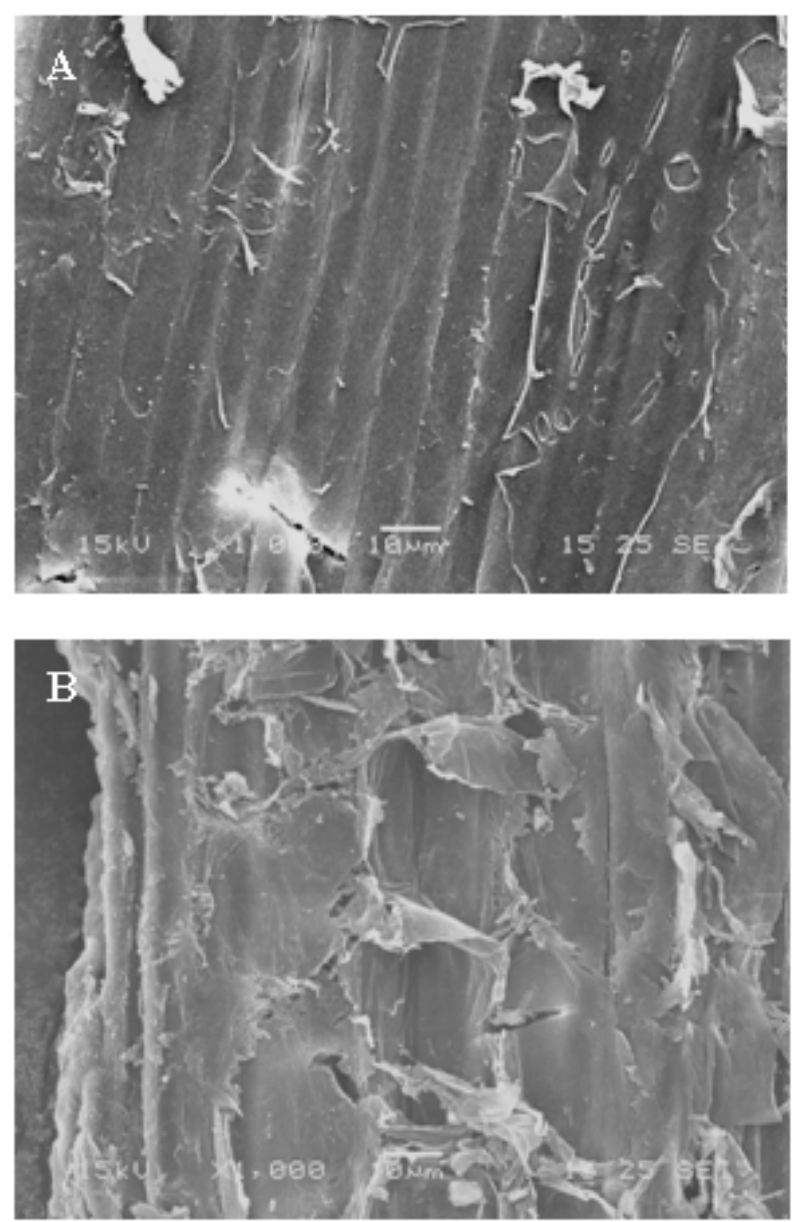

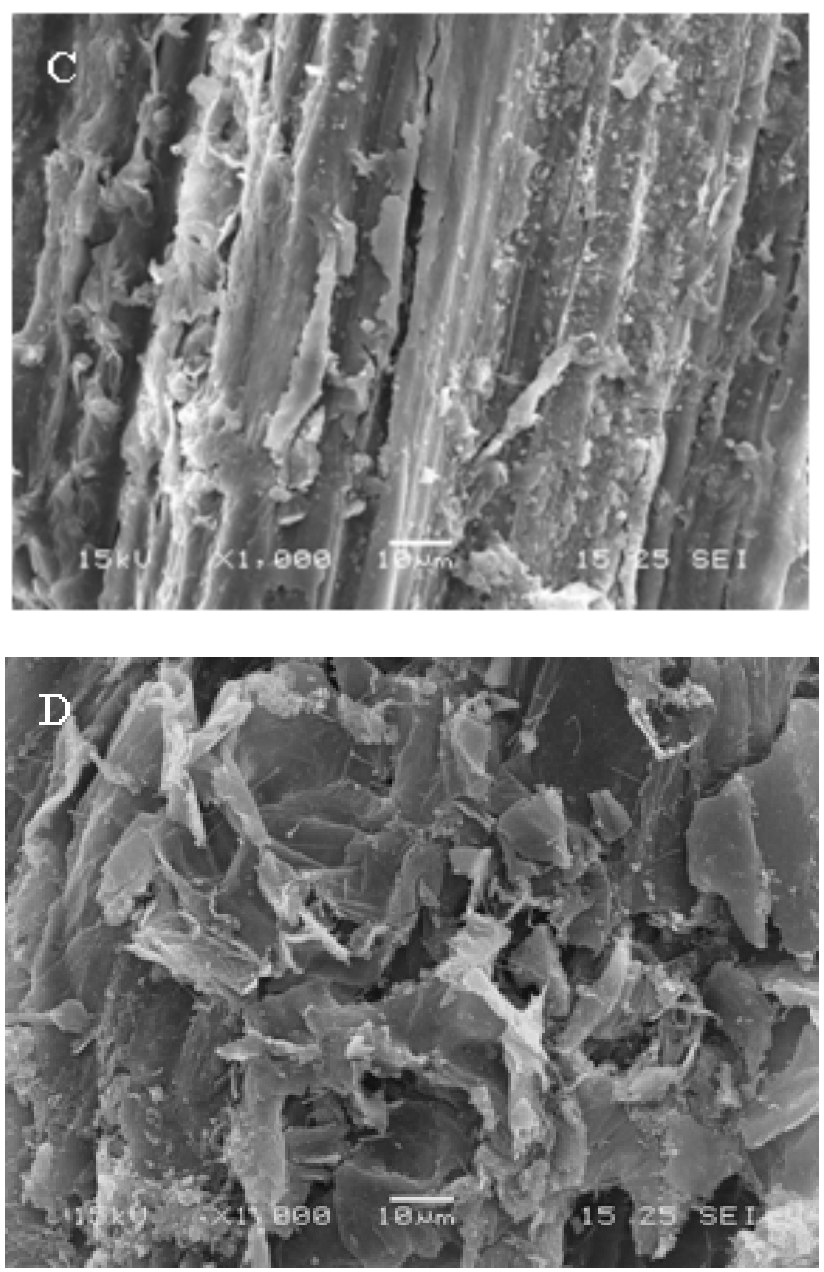

Figure 5. SEM of (A) untreated wheat straw; (B) untreated wheat straw after enzymatic hydrolysis at a cellulase loading of $25 \mathrm{FPU} / \mathrm{g}$ for $30 \mathrm{~h}$; (C) wheat straw pretreated at $121^{\circ} \mathrm{C} / 15 \mathrm{psi}$; (D) wheat straw pretreated at $121^{\circ} \mathrm{C} / 15 \mathrm{psi}$ followed by enzymatic hydrolysis at a cellulase loading of $25 \mathrm{FPU} / \mathrm{g}$ for 30 h.

\section{Enzymatic hydrolysis}

Cellulase is widely present in organisms. However, cellulase produced by different organisms is different in its components and ability to degrade cellulose. Most of the current studies on cellulase are focused on Truchoderma, especially $T$. reesei (24). Compared to Truchoderma, Penicillium can synthesize more balanced cellulose degrading enzyme system, which can compensate the insufficient production of glucosaccharase in Truchoderma. $P$. waksmanii F10-2 has high activity to degrade cellulose. Enzymatic hydrolysis of pretreated wheat straw was carried out by filtrate of $P$. waksmanii F10-2. The various parameters such as hydrolysis time, substrate concentration, temperature and $\mathrm{pH}$ were optimized to achieve maximum saccharification of wheat straw.

The effect of time on the enzymatic hydrolysis: We further determined the effect of enzymatic reaction time on the efficiency of hydrolysis for the pretreated wheat straw. The pretreated wheat straws were mixed with cellulase for $6-48 \mathrm{~h}$ and the concentration of released reducing sugar was measured every $6 \mathrm{~h}$. The results showed that as the enzymatic reaction time was increased, the concentration of the released reducing sugars was also increased (Fig. 6). The concentration of the reducing sugars was $343.95 \mathrm{mg}$ per 1 gram of substrate with a maximal saccharification rate of $43 \%$ at $30 \mathrm{~h}$ of enzymatic reaction. The content of reducing sugar was gradually decreased after $30 \mathrm{~h}$ of reaction. This might be due to the inhibition of the enzyme activity by the accumulated hydrolysis products.

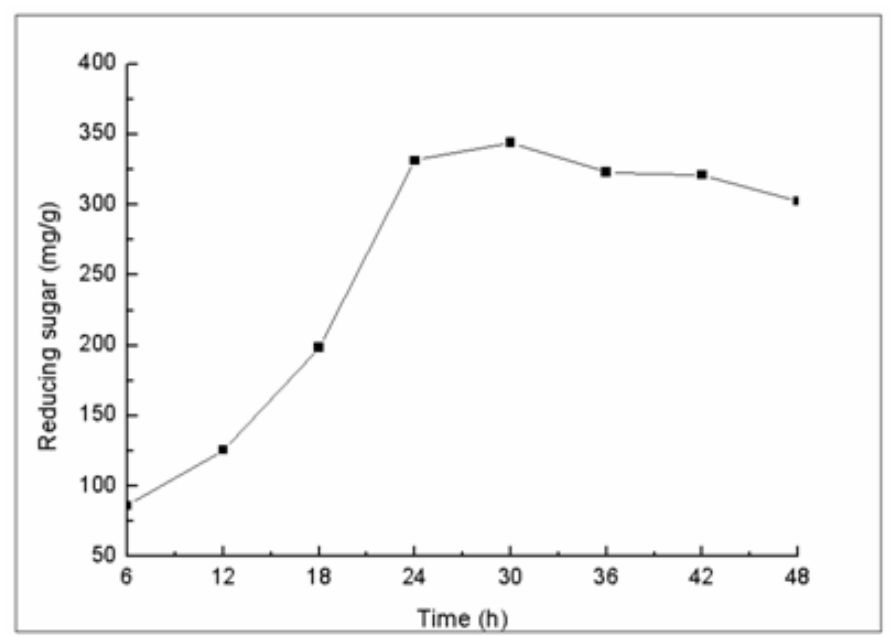

Figure 6. The effect of time on the efficiency of enzymatic hydrolysis.

Enzyme loading $25 \mathrm{FPU} / \mathrm{g}$, substrate concentration 1\% (w/v), temperature $50{ }^{\circ} \mathrm{C}, \mathrm{pH} 5.0$ 
The effect of substrate concentration on the enzymatic hydrolysis: The effect of substrate concentration on the efficiency of hydrolysis was determined by using $1 \%-10 \%$ of wheat straw pretreated with alkaline. The results showed that the maximal saccharification rate of $43.78 \%$ was achieved when the substrate concentration (pretreated wheat straw) was $3 \%$ (Fig. 7). At this substrate concentration, the reducing sugar was $350.18 \mathrm{mg}$ per 1 gram of substrate. When the substrate concentration was less than $3 \%$, the enzymatic reaction speed was increased as the substrate concentration was increased. Once the substrate was saturated and further increased, the concentration of reducing sugars was gradually decreased. Studies have shown that as the substrates were increased, the feedback inhibition by cellobiose and glucose was enhanced, leading to the reduced production of reducing sugars in the enzymatic reaction (25).

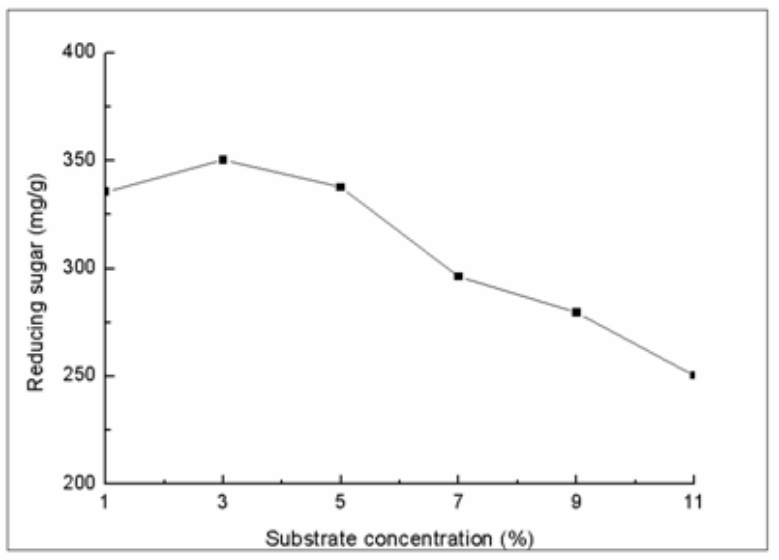

Figure 7. The effect of substrate concentration on the enzymatic hydrolysis.

Enzyme loading $25 \mathrm{FPU} / \mathrm{g}$, temperature $50^{\circ} \mathrm{C}, \mathrm{pH} 5.0$, reaction time $30 \mathrm{~h}$.

\section{The effect of temperature on the enzymatic hydrolysis:}

Temperature is an important factor, which influences not only the speed of enzymatic reaction, but alto the activity of the cellulose. Normally, as the temperature is increased in a certain range, the enzymatic reaction is accelerated. However, when the temperature is further increased beyond this range, the enzyme becomes denatured, leading to the reduced speed of enzymatic reaction. The optimal reaction temperature for cellulase is between $45^{\circ} \mathrm{C}$ and $55^{\circ} \mathrm{C}$. However, the optimal temperature varies for the cellulase from different sources and different enzymatic matrix. We showed here that the concentration of reducing sugars was increased with the reaction temperature increased (Fig. 8), and the maximal concentration of reducing sugar $(341.87 \mathrm{mg} / \mathrm{g}$ substrate) with a saccharification rate of $42.74 \%$ was achieved. When the temperature was further increased beyond $55{ }^{\circ} \mathrm{C}$, the concentration of reducing sugar was reduced. Thus, the optimal temperature for enzymatic hydrolysis was $55^{\circ} \mathrm{C}$.

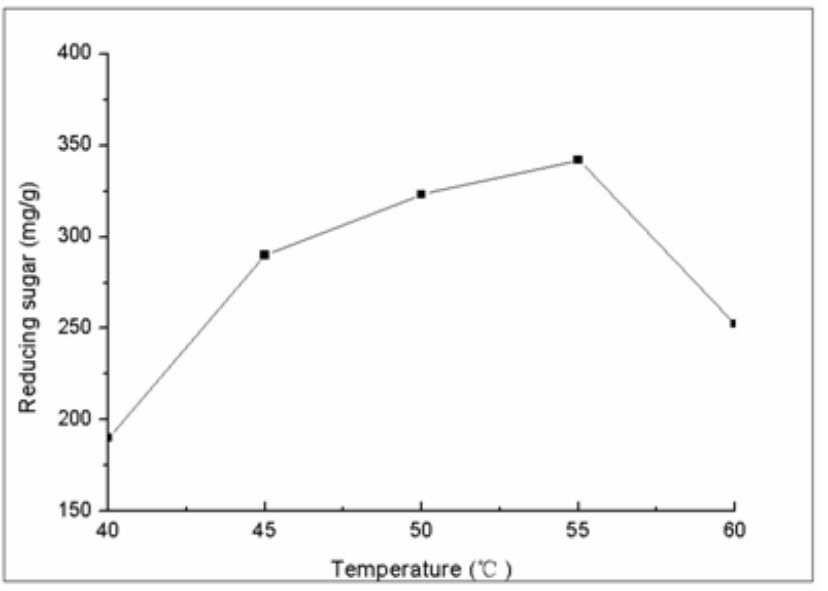

Figure 8. The effect of temperature on the enzymatic hydrolysis.

Enzyme loading $25 \mathrm{FPU} / \mathrm{g}$, substrate concentration $3 \%(\mathrm{w} / \mathrm{v}), \mathrm{pH} 5.0$, reaction time $30 \mathrm{~h}$.

The effect of pH on the enzymatic hydrolysis: The speed of the enzymatic reaction was determined under the condition of $\mathrm{pH} 4,4.5,5,5.5$ and 6 . The results showed that $\mathrm{pH}$ 5 achieved maximal concentration of reducing sugars with $350.03 \mathrm{mg}$ per 1 gram of substrate (Fig. 9). These results suggested that the activity was affected by the environmental $\mathrm{pH}$. Maximal reaction speed was achieved at $\mathrm{pH}$. When $\mathrm{pH}$ 
was higher or lower than 5 , the enzymatic reaction speed was reduced. Changes of $\mathrm{pH}$ may result in the loss of cellulase activity or dissociation between substrate and catalytic group of enzyme active center, leading to the reduced speed of enzymatic reaction. Therefore, $\mathrm{pH}$ should be controlled in the cellulase-catalyzed hydrolysis reaction to achieve maximal activity of cellulase.

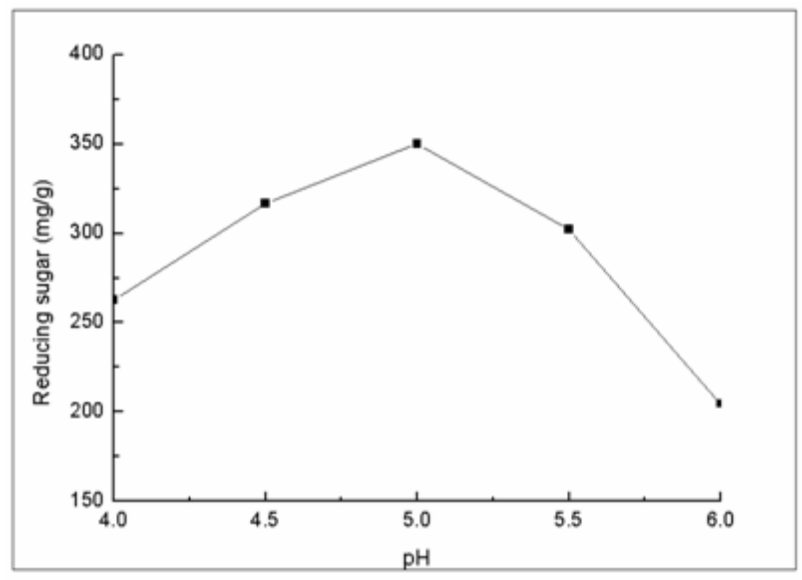

Figure 9. The effect of $\mathrm{pH}$ on the enzymatic hydrolysis.

Enzyme loading $25 \mathrm{FPU} / \mathrm{g}$, substrate concentration $3 \%(\mathrm{w} / \mathrm{v})$, temperature $50{ }^{\circ} \mathrm{C}$, reaction time $30 \mathrm{~h}$.

\section{CONCLUSION}

Many factors including the content of lignin, surface areas, crystallinity and degree of polymerization affect the efficiency of substrate hydrolysis by cellulase. Studies have shown that the main factor affecting the hydrolysis by cellulase is the accessible surface area of substrate, followed by the content of lignin and crystallinity (26). The purpose of pretreatment is to remove lignin and hemicellulose, reduce cellulose crystallinity and increase the porosity. Therefore, selecting appropriate pretreatment methods plays a significant role in increasing the efficiency of cellulose hydrolysis. The pretreatment method used in this study attempts to increase the accessible surface area, decrease the content of lignin and disrupt the polymerization of lignocellulose. Our results showed that milling of the wheat straw into the sizes of 120 meshes followed by treatment with $1.0 \%$ of $\mathrm{NaOH}$ for $1.5 \mathrm{~h}$ increased the content of cellulose by $44.52 \%$, while decreased the content of hemicellulose and lignin by $44.15 \%$ and $42.45 \%$, respectively. SEM and infrared spectrum analyses showed that the surface structure of the wheat straw and lignin was significantly changed after pretreatment, which is more favorable for the hydrolysis reaction. The optimal condition for the cellulase-catalyzed hydrolysis was (1) $30 \mathrm{~h}$ of reaction; (2) $3 \%$ of substrate; (3) $55^{\circ} \mathrm{C}$ and (4) $\mathrm{pH} 5.0$.

\section{ACKNOWLEDGEMENTS}

The authors wish to acknowledge financial support from the Key Scientific and Technological Innovation Special Projects of Shaanxi“13115” (No. 2007ZDKG-04).

\section{REFERENCES}

1. Aden, A.; Ruth, M.; Ibsen, K.; Jechura, J.; Neeves, K.; Sheehan, J.; Wallace, B.; Montague, L.; Slayton, A.; Lukas, J. (2002). Lignocellulosic biomass to ethanol process design and economics utilizing co-current dilute acid prehydrolysis and enzymatic hydrolysis for corn stover. NREL/TP-510-32438: http://www.nrel.gov.

2. Agarwal, U.P.; Atalla, R.H.; Forsskahl, I. (1995). Sequential treatment of mechanical and chemi-mechanical pulps with light and heat: A Raman spectroscopic study. Holzforschung. 49, 300-312.

3. Chang, V.S. ; Holtzapple, M.T. (2000). Fundamental factors affecting biomass enzymatic reactivity. Appl. Biochem. Biotechnol. 84-86, 5-37.

4. Chang, C.C.; Ng, C.C.; Wang, C.Y.; Shyu, Y.T. (2009). Activity of cellulase from Thermoactinomycetes and Bacillus spp. isolated from Brassica waste compost. Braz. J. Microbiol. 66, 304-308.

5. Fan, L.T.; Lee, Y. (1980). Beardmore DH. Mechanism of the enzymatic hydrolysis of cellulose: Effects of major structural features of cellulose on enzymatic hydrolysis. Biotechnol. Bioeng. 22, 177-199.

6. Goering, H.K.; Van Soest, P.J. (1970). Forage fiber analysis. Agriculture handbook. Agricultural Research Services, United States Department of Agriculture, No.379.

7. Gregg, D.J.; Saddler, J.N. (1996). Factors affecting cellulose hydrolysis and the potential of enzyme recycle to enhance the 
efficiency of an integrated wood to ethanol process. Biotechnol. Bioeng. 51, 75-383.

8. Hendriks, A.T.W.M.; Zeeman, G. (2009). Pretreatments to enhance the digestibility of lignocellulosic biomass. Bioresour. Technol. 100, 10-18.

9. Henning, J.; Tomy, E.; Johan, B.; Folke, T.; Lisbeth, O. (2003) Purification and characterization of five cellulases and one xylanase from Penicillium brasilianumIBT 20888. Enzyme. Microb. Technol. 32, 851861.

10. Hsu, T.A. (1996). Pretreatment of biomass. In: Wyman, C.E. (Ed.), Handbook on Bioethanol: Production and Utilization. Taylor \& Francis, Washington, DC, 179-195.

11. Koullas, D.P.; Christakopoulos, P.; Kekos, D.; Macris, B.J.; Koukios, E.G. (1992). Correlating the effect of pretreatment on the enzymatic hydrolysis of straw. Biotechnol. Bioeng. 39, 113-116.

12. Krishna, S.H.; Chowdary, G.V. (2000). Optimization of simultaneous saccharification and fermentation for the production of ethanol from lignocellulosic biomass. J. Agric. Food Chem. 48, 1971-1976.

13. Laureano-Perez, L.; Teymouri, F.; Alizadeh, H.; Dale, B.E. (2005). Understanding factors that limit enzymatic hydrolysis of biomass. Appl. Biochem.Biotechnol. 121-124, 1081-1099.

14. Lynd, L.R.; Elander, R.T.; Wyman, C.E. (1996). Likely features and costs of mature biomass ethanol technology. Appl. Biochem. Biotech. 57/58, 741-761

15. Mandels, M.; Andreotti, R.; Roche, C. (1976). Measurement of saccharifying cellulose. Biotechnol. Bioeng. Symp. 6, 21-33.

16. Miller, G.L. (1959). Use of dinitrosalicylic acid reagent for determination of reducing sugar. Anal. Biochem. 31, 426-428.

17. Mosier, N.; Wyman, C.; Dale, B.; Elander, R.; Lee, Y.Y.; Holtzapple, M.; Ladish, M. (2005). Features of promising technologies for pretreatment of lignocellulosic biomass. Bioresour. Technol. 96, 673686.
18. Puri, V.P.; Mamers, H. (1983). Explosive pretreatment of lignocellulosic residues with high-pressure carbon dioxide for the production of fermentation substrates. Biotechnol. Bioeng. 25, 3149-3161.

19. Séné, C.F.B.; McCann, M.C.; Wilson, R.H.; Grinter, R. (1994). Fouriertransfor raman and Fourier-transform infrared spectroscopy: An investigation of five higher plant cell walls and their components. Plant Physiol. 106, 1623-1631.

20. Soto, M.L.; Dominguez, M.J.; Lema, J.M. (1994). Enzymatic saccharification of alkali treated sunflower hulls. Bioresour. Technol. 49, 53-9.

21. Stewart, D.; Yahiaoui, N.; McDougall, G.J.; Myton, K.; Marque, C.; Boudet, A.M.; Haigh, J. (1997). Fourier-transform infrared and Raman spectroscopic evidence for the incorporation of cinnamaldehydes into the lignin of transgenic tobacco (Nicotiana tabacum L.) plants with reduced expression of cinnamyl alcohol dehydrogenase. Planta. 201, 311-318.

22. Sun, Y.; Cheng, J. (2002). Hydrolysis of lignocellulosic materials for ethanol production: a review. Bioresour. Technol. 83, 1-11.

23. Thomas, F.; Jennings, L.; Mulcahy, P. (2007). Compositional analysis of lignocellulosic materials: Evaluation of methods used for sugar analysis of waste paper and straw. Bioresour. Technol. 98, 3026-3036.

24. Zeng, M.; Mosier, N.S.; Huang, C.P.; Sherman, D.M.; Ladisch, M.R. (2007). Microscopic examination of changes of plant cell structure in corn stover due to hot water pretreatment and enzymatic hydrolysis. Biotechnol. Bioeng. 97, 265-278.

25. Zhong, R.Q.; Morrison, W.H.; Himmelsbach, D.S.; Poole, F.L.; Ye, Z.H. (2000). Essential role of caffeoyl coenzyme a O-methyltransferase in lignin biosynthesis in woody poplar plants. Plant Physiol. 124, 563-577.

26. Zhu, S.D.; Wu, Y.X.; Yu, Z.N.; Chen, Q.M.; Wu, G.Y.; Yu, F.Q.; Wang, C.W.; Jin, S.W. (2006). Microwave-assisted Alkali Pre-treatment of Wheat Straw and its Enzymatic Hydrolysis. Biosyst. Eng. 4, 437-442. 